\title{
Review Article \\ Hydrogen Sulfide as a Potential Alternative for the Treatment of Myocardial Fibrosis
}

\author{
Se Chan Kang $\mathbb{D},{ }^{1}$ Eun-Hwa Sohn, ${ }^{2}$ and Sung Ryul Lee $\mathbb{D}^{3}$ \\ ${ }^{1}$ Department of Oriental Medicine Biotechnology, College of Life Sciences, Kyung Hee University, Yongin 17104, Republic of Korea \\ ${ }^{2}$ Department of Herbal Medicine Resource, Kangwon National University, Samcheok 25949, Republic of Korea \\ ${ }^{3}$ Department of Convergence Biomedical Science, Cardiovascular and Metabolic Disease Center, College of Medicine, Inje University, \\ Busan 47392, Republic of Korea
}

Correspondence should be addressed to Sung Ryul Lee; lsr1113@inje.ac.kr

Received 4 November 2019; Accepted 10 December 2019; Published 23 January 2020

Guest Editor: Mario Fontana

Copyright (C) 2020 Se Chan Kang et al. This is an open access article distributed under the Creative Commons Attribution License, which permits unrestricted use, distribution, and reproduction in any medium, provided the original work is properly cited.

Harmful, stressful conditions or events in the cardiovascular system result in cellular damage, inflammation, and fibrosis. Currently, there is no targeted therapy for myocardial fibrosis, which is highly associated with a large number of cardiovascular diseases and can lead to fatal heart failure. Hydrogen sulfide $\left(\mathrm{H}_{2} \mathrm{~S}\right)$ is an endogenous gasotransmitter similar to nitric oxide and carbon monoxide. $\mathrm{H}_{2} \mathrm{~S}$ is involved in the suppression of oxidative stress, inflammation, and cellular death in the cardiovascular system. The level of $\mathrm{H}_{2} \mathrm{~S}$ in the body can be boosted by stimulating its synthesis or supplying it exogenously with a simple $\mathrm{H}_{2} \mathrm{~S}$ donor with a rapid- or slow-releasing mode, an organosulfur compound, or a hybrid with known drugs (e.g., aspirin). Hypertension, myocardial infarction, and inflammation are exaggerated when $\mathrm{H}_{2} \mathrm{~S}$ is reduced. In addition, the exogenous delivery of $\mathrm{H}_{2} \mathrm{~S}$ mitigates myocardial fibrosis caused by various pathological conditions, such as a myocardial infarct, hypertension, diabetes, or excessive $\beta$-adrenergic stimulation, via its involvement in a variety of signaling pathways. Numerous experimental findings suggest that $\mathrm{H}_{2} \mathrm{~S}$ may work as a potential alternative for the management of myocardial fibrosis. In this review, the antifibrosis role of $\mathrm{H}_{2} \mathrm{~S}$ is briefly addressed in order to gain insight into the development of novel strategies for the treatment of myocardial fibrosis.

\section{Introduction}

Although fibrosis is an essential process for the restoration and maintenance of organ integrity after injury or stress via the timely deposition of the extracellular matrix (ECM), the aberrant accumulation of stiff and disorganized ECM progressively disrupts tissue function and can ultimately cause organ failure [1-5]. Myocardial fibrosis is a hallmark feature of heart failure and is associated with hypertension, myocardial infarction (MI), and pathological hypertrophy followed by injury and stress $[1,2]$. Systemic responses induced by the decline in systolic function, particularly neurohumoral activation (angiotensin-aldosterone system and $\beta$-adrenergic nervous system), are associated with the progression of heart failure (HF). Traditional therapies, such as $\beta$-blockers and renin-angiotensin-aldosterone system (RAAS) inhibitors, have been found to have beneficial effects in patients with cardiac fibrosis in clinical trials [6, 7]. However, these conventional drugs do not aim at directly curing myocardial fibrosis but rather aim at alleviating the underlying cardiac dysfunction mechanisms indirectly [6]. Therefore, great effort is currently being devoted to research on the development of therapeutic interventions for decreasing the high morbidity and mortality associated with myocardial fibrosis, particularly on the identification and modulation of its core mechanisms [1-4].

Despite its previous characterization as a toxic gas with a rotten egg smell, $\mathrm{H}_{2} \mathrm{~S}$ is beginning to be associated with a growing family of gasotransmitters, with properties similar to nitric oxide (NO) and carbon monoxide (CO) [8-10]. As a gasotransmitter, $\mathrm{H}_{2} \mathrm{~S}$ is involved in both the physiology and pathophysiology of the nervous, cardiovascular, and gastrointestinal systems via its antioxidant, anti-inflammatory [11], antinociceptive, antihypertensive, neuromodulative, 
and cytoprotective effects [9, 12-14]. The modulation of signals involved in myocardial fibrosis, and thereby the attenuation of pathological fibrosis, is an area of intense scientific interest due to its evident therapeutic implications for the treatment of $\mathrm{HF}$ [15]. Reduced levels of $\mathrm{H}_{2} \mathrm{~S}$ have been identified in patients with ischemia [16], diabetes [17, 18], high-fat diet-induced cardiomyopathy [19], hypertension [20], and heavy metal detoxifications, such as nickel detoxification [21].

The role of an exogenously delivered $\mathrm{H}_{2} \mathrm{~S}$ in antifibrosis has been identified in a variety of experimental settings (Table 1). In this review, myocardial fibrosis and the potential antifibrosis effects of $\mathrm{H}_{2} \mathrm{~S}$ are outlined. $\mathrm{H}_{2} \mathrm{~S}$ is not the sole gasotransmitter in the body and can interact with other gasotransmitters including $\mathrm{NO}$ and $\mathrm{CO}$. In addition to direct chemical crosstalk, $\mathrm{NO}, \mathrm{CO}$, and $\mathrm{H}_{2} \mathrm{~S}$ compete in heme- or metal-containing proteins and at the posttranslational modification sites of proteins [9]. Thus, various types of crosstalk between $\mathrm{CO}, \mathrm{H}_{2} \mathrm{~S}$, and $\mathrm{NO}$ in the cardiovascular system exist [9]. For example, nitrosopersulfide, polysulfides, and dinitrososulfite can be formed by the interaction of $\mathrm{NO}$ and $\mathrm{H}_{2} \mathrm{~S}$. These anionic intermediates modulate the bioavailability of $\mathrm{NO} / \mathrm{HNO}$ or $\mathrm{H}_{2} \mathrm{~S} /$ sulfane sulfur and are thus responsible for distinct physiological consequences [22]. Although bioactive intermediates that form interactions with each other are an emerging research field, the modulatory role of $\mathrm{H}_{2} \mathrm{~S}$ intermediates in myocardial fibrosis is beyond our current review.

\section{Hydrogen Sulfide}

2.1. Synthesis of $\mathrm{H}_{2} \mathrm{~S} . \mathrm{H}_{2} \mathrm{~S}$ is the simplest thiol, which are sulfur analogs of alcohol (R-SH); is associated with the smell of rotten eggs; and has a high redox potential [23]. As depicted in Figure $1, \mathrm{H}_{2} \mathrm{~S}$ is endogenously synthesized from L-cysteine or L-homocysteine via cystathionine $\beta$-synthase (CBS) and cystathionine $\gamma$-lyase (CSE), which are pyridoxal $5^{\prime}$-phosphate-dependent cytosolic enzymes in the transsulfuration pathway [24]. CSE is involved in the cardiovascular system, especially in myocardial cells [25], vascular smooth muscle cells [26, 27], and endothelial cells [28], whereas CBS is predominantly found in the nervous system [29]. In the mitochondria, cysteine aminotransferase (CAT) catalyzes L-cysteine and glutamate to 3 -mercaptopyruvate and $\alpha$-ketoglutarate. Then, 3-mercaptopyruvate is metabolized to pyruvate and $\mathrm{H}_{2} \mathrm{~S}$ via 3-mercaptopyruvate sulfurtransferase (3-MST) [23]. Nonenzymatically, $\mathrm{H}_{2} \mathrm{~S}$ can also be released from preexisting intracellular sulfur stores (sulfane sulfur) through the activities of reducing agents $[24,30]$. For example, the production of $\mathrm{H}_{2} \mathrm{~S}$ from sulfur-containing amino acids (e.g., cysteine) via iron and vitamin $\mathrm{B}_{6}$ under physiological conditions has been found in red blood cells and tissues [31]. However, the exact biological roles of this nonenzymatic production of $\mathrm{H}_{2} \mathrm{~S}$ have not yet been established.

2.2. Exogenous $\mathrm{H}_{2} \mathrm{~S} . \mathrm{H}_{2} \mathrm{~S}$ can be inhaled directly, and the regulated inhalation of $\mathrm{H}_{2} \mathrm{~S}$ is an effective method for the control of hemorrhages in preclinical studies [32]. Although the inhalation of $\mathrm{H}_{2} \mathrm{~S}$ gas produces few byproducts, controlling its dosage and handling the specialized equipment needed for its delivery is difficult. There are a number of compounds that have been synthesized specifically to deliver therapeutic $\mathrm{H}_{2} \mathrm{~S}$ to tissues $[9,23,33]$, including inorganic sulfide salts (e.g., NaHS), synthetic organic compounds with a slow $\mathrm{H}_{2} \mathrm{~S}$-releasing mode, conventional drug molecules coupled with an $\mathrm{H}_{2} \mathrm{~S}$-donating group, cysteine analogs, nucleoside phosphorothioates, and plant-derived polysulfides (Table 1).

2.3. Modulation of $\mathrm{H}_{2} \mathrm{~S}$ Level. The bioavailability of $\mathrm{H}_{2} \mathrm{~S}$ inside the cell is primarily regulated by $\mathrm{H}_{2} \mathrm{~S}$-synthesizing enzymes (CSE, CBS, or 3-MST) and $\mathrm{H}_{2} \mathrm{~S}$-oxidizing enzymes located in the mitochondria (e.g., sulfide quinone reductase, persulfide dioxygenase, and thiosulfate sulfurtransferase) [9]. Cysteine and its derivatives can be used to boost $\mathrm{H}_{2} \mathrm{~S}$ synthesis [33]. MicroRNA (miRNA) controls gene expression at the posttranscriptional level [34] and is one of the main factors involved in the upregulation of CSE expression [16]. Interestingly, currently used drugs, including angiotensinconverting enzyme (ACE) inhibitors (e.g., ramipril) [35], statins [36], calcium channel antagonists (e.g., amlodipine) [37], digoxin [38], vitamin $\mathrm{D}_{3}$ [39], aspirin [40], metformin [40], and others [23], may increase the production of $\mathrm{H}_{2} \mathrm{~S}$. For example, statins can increase $\mathrm{H}_{2} \mathrm{~S}$ synthesis via Aktmediated upregulation of CSE [36] or suppress $\mathrm{H}_{2} \mathrm{~S}$ degradation by decreasing the concentration of coenzyme $\mathrm{Q}$, which is a sulfide quinone reductase cofactor [41]. It is worth noting that either exogenously supplied or endogenously produced $\mathrm{H}_{2} \mathrm{~S}$ can be stored in the body in the form of bound sulfane, which is a reductant labile sulfur (e.g., persulfide (R-S-S$\mathrm{SH})$, polysulfide $\left(\mathrm{RSS}_{\mathrm{n}} \mathrm{SR}\right)$, and protein-associated sulfur, among others) [42]. With regard to the dietary supplementation of $\mathrm{H}_{2} \mathrm{~S}$, garlic and garlic-derived organic polysulfides, such as diallyl trisulfide (DATS) and diallyl disulfide (DADS), behave as $\mathrm{H}_{2} \mathrm{~S}$ donors with the aid of a biological thiol (e.g., glutathione), maintained via pentose phosphate pathway-mediated NADPH production [43].

2.4. Functional Roles of $\mathrm{H}_{2} \mathrm{~S}$ in the Biological System. $\mathrm{H}_{2} \mathrm{~S}$ displays antioxidant effects through the direct quenching of reactive oxygen species (ROS) via a hydrosulfide anion (HS-), which is a powerful one-electron chemical reductant that is dissociated from $\mathrm{H}_{2} \mathrm{~S}$ in physiological fluid [12]. $\mathrm{H}_{2} \mathrm{~S}$ derivatives such as nitrosopersulfide, polysulfides, and dinitrososulfite may also be involved in redox switching in biological systems by generating redox congeners like nitroxyl, nitrous oxide, and sulfane sulfur [22]. NaHS may indirectly suppress ROS production through the $\mathrm{H}_{2} \mathrm{~S}$-mediated activation of a copper/zinc superoxide $[44,45]$. In addition, $\mathrm{H}_{2} \mathrm{~S}$ induces the suppression of oxidative stress through the activation of Nrf2 (transcription factor nuclear factor (erythroid-derived 2)-like 2) and NAD-dependent deacetylase sirtuin (SIRT)-3, resulting in increased expression of other antioxidant enzymes and proteins (e.g., GSH and thioredoxin-1) [46, 47]. The low concentration of $\mathrm{H}_{2} \mathrm{~S}$ may cause oxidative stress, resulting in the depletion of tetrahydrobiopterin, which determines the levels of endothelial nitric oxide synthase (eNOS) activity [48]. As latent matrix metalloproteinases (MMPs) can be activated by oxidative stress [49], 


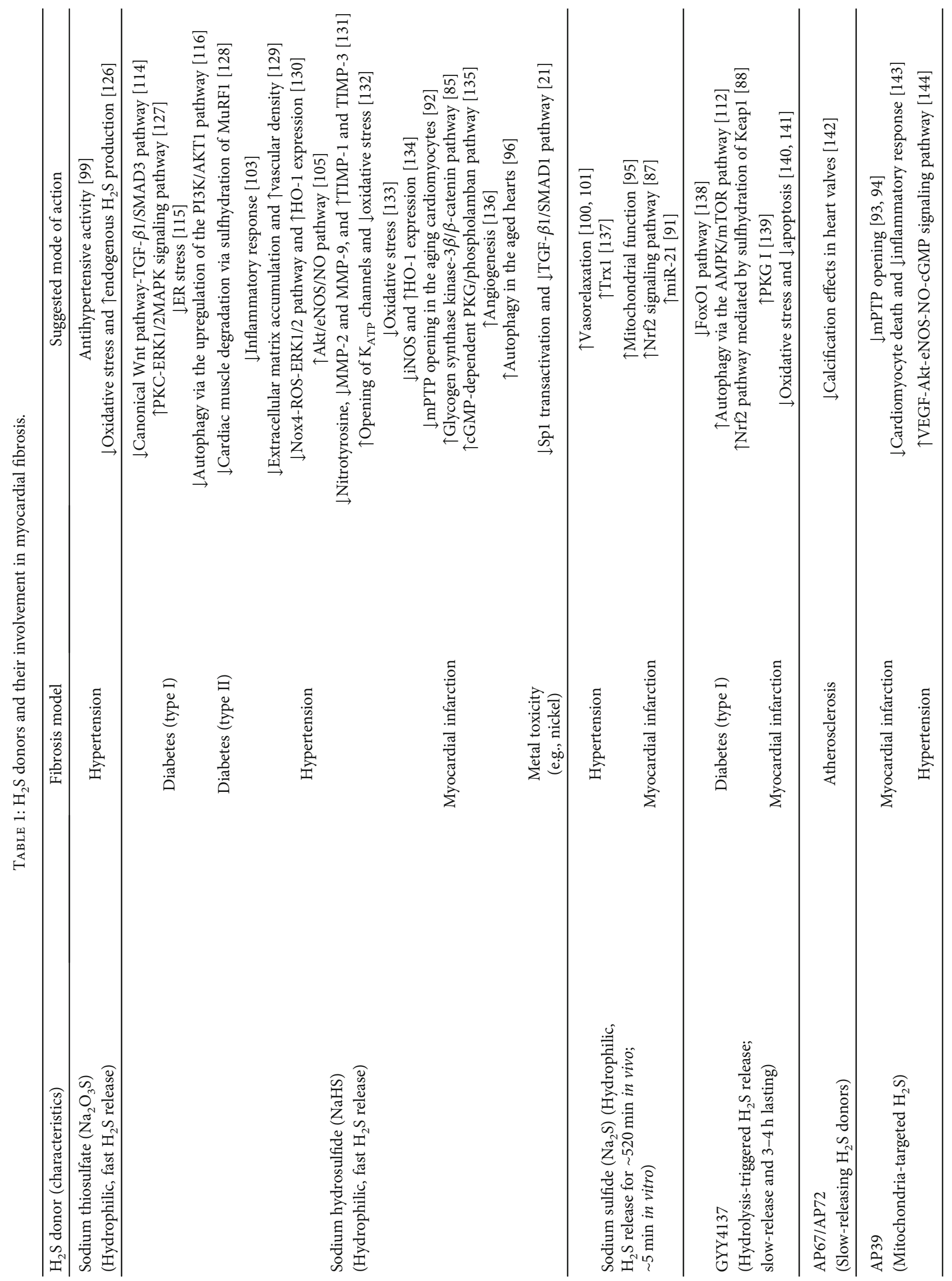




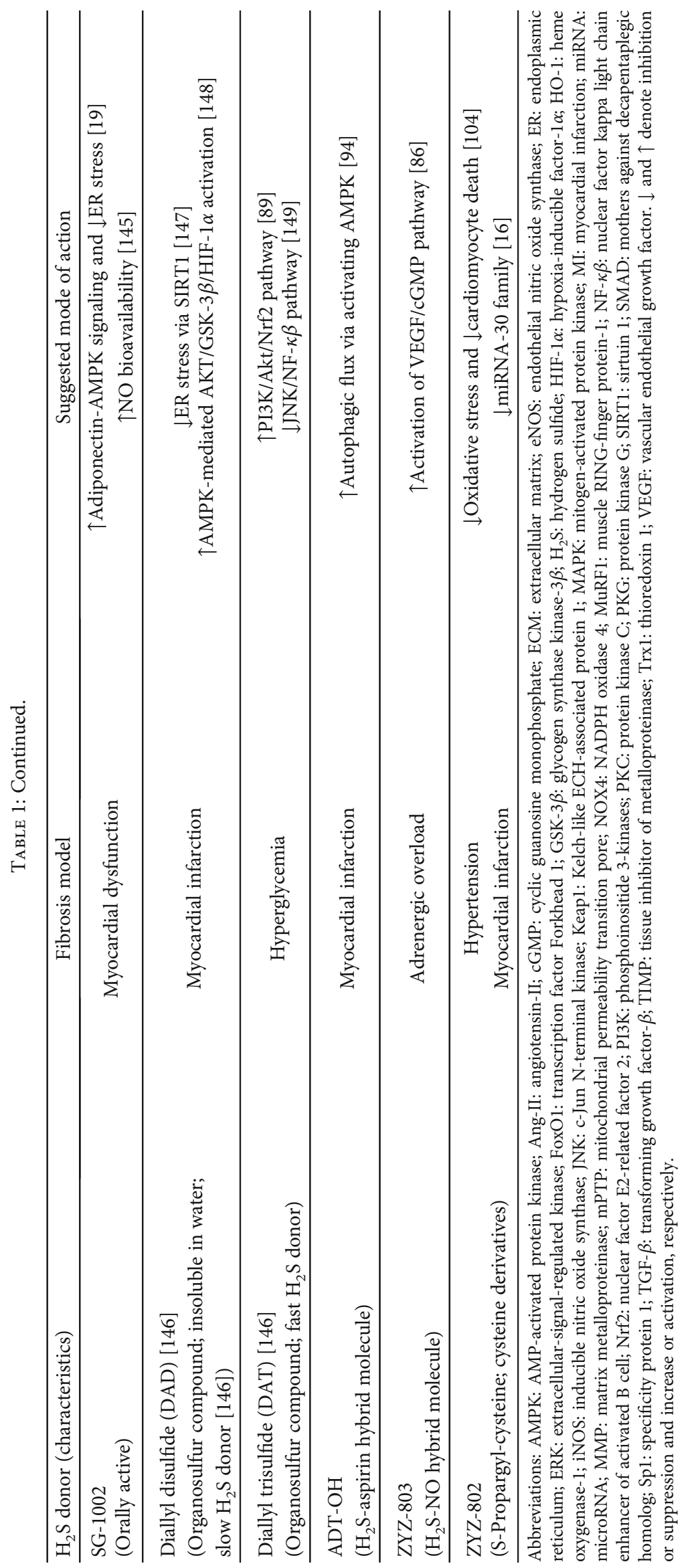




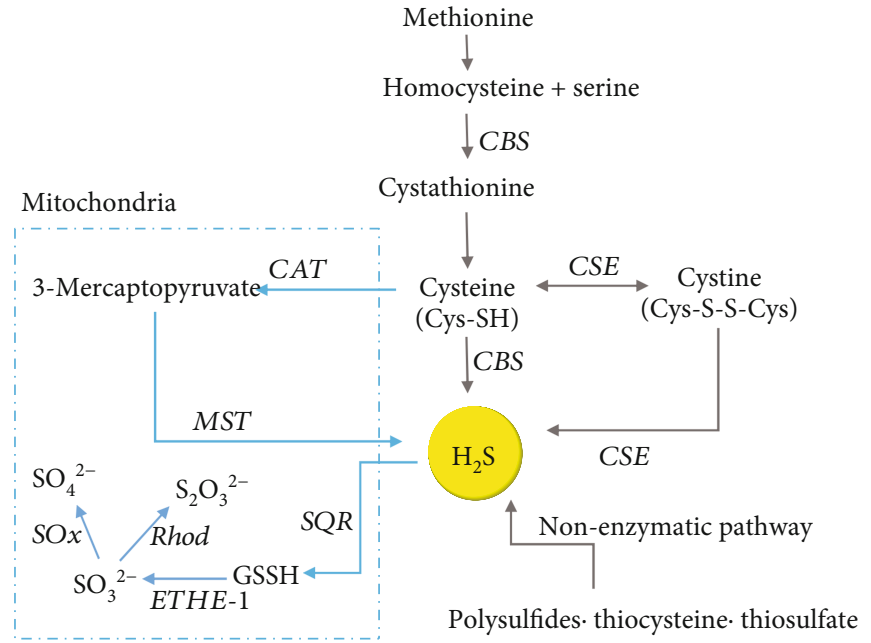

FIGURE 1: Endogenous $\mathrm{H}_{2} \mathrm{~S}$ production. Abbreviations: CAT: cysteine aminotransferase; CBS: cystathionine- $\beta$-synthase; CSE: cystathionine$\gamma$-lyase; ETHE-1: persulfide dioxygenase; GSSH: oxidized glutathione; MST: 3-mercaptopyruvate sulfurtransferase; Rhod: rhodanase; SOx: sulfur dioxygenase; SQR: sulfide quinone oxidoreductase.

the antioxidant capacity of $\mathrm{H}_{2} \mathrm{~S}$ may be involved, at least in part, in the suppression of MMP activation.

$\mathrm{H}_{2} \mathrm{~S}$ is able to modulate the functions of proteins containing prosthetic metal complexes in acceptor proteins due to its high reactivity with metal ions [50,51]. For example, polysulfides bind to inactive ferric indoleamine 2,3-dioxygenase (IDO1), which strongly suppresses the immune response, thereby reducing it to its oxygen-binding ferrous state, thus activating IDO1 to maximal turnover [52]. As such, $\mathrm{H}_{2} \mathrm{~S}$ is able to elicit an anti-inflammatory response through the activation of IDO1. $\mathrm{H}_{2} \mathrm{~S}$ can lead to protein S-sulfhydration (sulfuration or persulfidation) by covalently converting the $-\mathrm{SH}$ group of cysteine into an -SSH group in the protein [53], thereby altering the activities of various enzymes, including that of $\mathrm{F}_{1} \mathrm{~F}_{0}$-ATPase [54], the ATP-sensitive potassium $\left(\mathrm{K}_{\mathrm{ATP}}\right)$ channel [55], and the phosphatase and tensin homo$\log$ (PTEN) [56]. In addition, protein sulfhydration changes the localization and stability of proteins inside cells and increases the resistance of proteins to oxidative stresses $[54,55] . \mathrm{H}_{2} \mathrm{~S}$ can activate soluble guanylyl cyclase (sGC) via direct heme binding [57] or by the inhibition of the cGMP phosphodiesterase (PDE) activity [57], resulting in the activation of cyclic GMP (cGMP)-protein kinase G (PKG) pathways.

The bioavailability of $\mathrm{H}_{2} \mathrm{~S}$ may play an important role in the integrated stress response, that is, in coping with changes to the cellular environment $[58,59] . \mathrm{H}_{2} \mathrm{~S}$ transiently increases the phosphorylation of eukaryotic initiation factor 2 (eIF $2 \alpha$ ) via the inhibition of protein phosphatase-1 (PP1c) via $\mathrm{H}_{2} \mathrm{~S}$-driven persulfidation [59], thereby inducing a transient adaptive reprogramming of global mRNA translation independent of upstream kinases [59]. As an epigenetic modulator, $\mathrm{H}_{2} \mathrm{~S}$ can modify the expression of Brahmarelated gene $1(\mathrm{Brg} 1)$ at the promoter region, thus suppressing the transcriptional activity of the ATP-dependent chromatin remodeling complex [60]. This suppressive activity of $\mathrm{H}_{2} \mathrm{~S}$ in the expression of $\mathrm{Brg} 1$ contributes to the inhibition of vascular smooth muscle cell proliferation [60]. $\mathrm{H}_{2} \mathrm{~S}$ may be involved in the decrease of the lysine acetylation of enzymes involved in fatty acid $\beta$-oxidation and glucose oxidation in diabetic conditions, thereby exerting a beneficial effect on cardiac energy substrate utilization by favoring a switch from fatty acid oxidation to glucose oxidation [61].

Mitochondrial damage associated with cardiovascular pathological stimuli, including oxidative stress, the overactivation of the renin-angiotensin-aldosterone and adrenergic systems, and the dysfunction of growth hormones, plays a central role in the loss of ischemic, and even nonischemic, cardiomyocytes $[62,63]$. The levels of mitochondrial DNA (mtDNA) content are dramatically reduced in CSE geneknockout mice; however, this reduction can be reversed via the exogenous delivery of $\mathrm{H}_{2} \mathrm{~S}$ [64]. $\mathrm{H}_{2} \mathrm{~S}$ can induce the replication of mtDNA and mitochondrial biogenesis by suppressing the methylation of mitochondrial transcription factor A (TFAM) [64]. In a different way, $\mathrm{H}_{2} \mathrm{~S}$ may be involved in the stimulation of cardiac mitochondrial biogenesis through the activation of the $5^{\prime}$ AMP-activated protein kinase (AMPK)-peroxisome proliferator-activated receptor gamma coactivator 1-alpha (PGC1 $\alpha$ ) pathway [65]. The sulfhydration of AMPK and protein phosphatase 2A (PP2A), which leads to the activation of AMPK and the inhibition of PP2A, respectively, has been suggested as a mechanism that may be involved in the $\mathrm{H}_{2} \mathrm{~S}$-mediated stimulation of mitochondrial biogenesis under nonstressed conditions [65].

\section{Myocardial Fibrosis and Antifibrosis Potential of $\mathrm{H}_{2} \mathrm{~S}$}

3.1. Myocardial Fibrosis. The heart is a highly organized structure composed of cardiomyocytes and noncardiomyocytes such as fibroblasts (nonexcitable cells of mesenchymal origin), endothelial cells, and vascular smooth muscle cells $[66,67]$. Maladaptive crosstalk between cardiomyocytes and noncardiomyocytes responding to pathological stress may result in myocardial fibrosis, adverse remodeling, and 


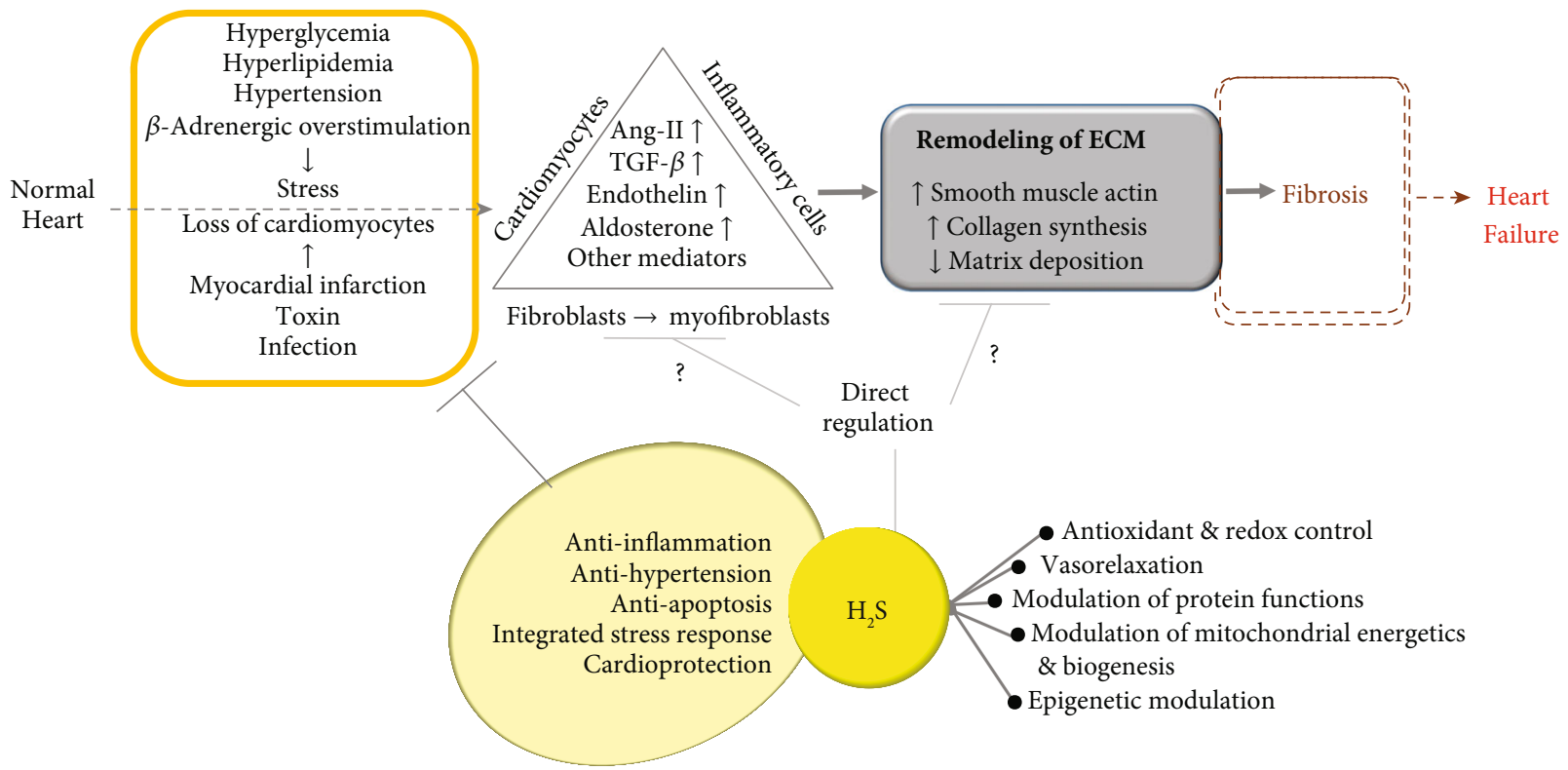

Figure 2: Simplified process of myocardial fibrosis and possible antifibrosis roles of $\mathrm{H}_{2} \mathrm{~S}$. Abbreviations: Ang-II: angiotensin-II; ECM: extracellular matrix; $\mathrm{H}_{2} \mathrm{~S}$ : hydrogen sulfide; TGF- $\beta$ : transforming growth factor- $\beta$.

arrhythmogenesis. Myocardial fibrosis is a reparative process involving the restoration of cardiomyocytes from cell death or sustained stress and is involved in maintaining the integrity of the heart, an action exerted mainly by the fibrillar, collagen-rich extracellular matrix (ECM), in the short term [68]. However, reactive fibrosis, such as interstitial and perivascular fibrosis [69], contributes to the progressive architectural remodeling of the heart as a result of the formation and deposition of excess fibrous connective tissue [70]. RAAS, transforming growth factor- $\beta$ (TGF- $\beta$ ), and $\beta$-adrenergic systems are common contributors to cardiac remodeling. These systems are connected to each other in an auto-/paracrine manner as a part of a larger signaling network [71]. During the progression of myocardial fibrosis, various distinct immunological and molecular mechanisms are interconnected via interactions between various cells, including macrophages, myofibroblasts, and matrices [68, 70, 72, 73]. As depicted in Figure 2, the loss of cardiomyocytes driven by various injurious agents and stresses has a detrimental effect on the architecture and function of the heart due to the negligible regenerative capacity of the heart, especially with regard to cardiomyocytes [72, 74]. Inflammatory cells, such as macrophages, appear in damaged regions of the heart and are tasked with removing the necrotic cardiomyocyte debris. TGF- $\beta$ is the best-known fibrogenic growth factor involved in cardiac fibrosis, even though a baseline level of TGF- $\beta$ signaling or an early-responsive increase in TGF- $\beta$ may protect the heart from acute injury [75]. It has been demonstrated that angiotensin-II (Ang-II) is an important mediator of cardiac fibrosis, working with the TGF- $\beta$ in the fibrotic response, due to the coexistence of TGF- $\beta$ receptors and Ang-II receptors in cardiomyocytes, inflammatory cells, and cardiac fibroblasts. TGF- $\beta 1$ triggers the appearance of inflammatory cells and myofibroblasts at the site of injury $[75,76]$ and stimulates the deposition of ECM, including fibronectin, fibrillar collagen types I and III, and proteoglycans. During this initial stage, in addition to the production of inflammatory cytokines, inflammatory cells secrete AngI, which is converted to Ang-II via the action of ACE. AngII plays a pivotal role in stimulating TGF- $\beta$ production, prompting the proliferation of circumambient fibroblasts and their transdifferentiation into myofibroblasts. The pool of fibroblasts can be enlarged by the transformation of either circulating bone marrow cells or endothelial/epithelial cells into fibroblasts $[66,77]$. During the proliferative phase of cardiac repair, fibroblasts undergo transdifferentiation into contractile myofibroblasts, secreting large amounts of matrix proteins, such as collagens [66]. Then, the scar tissue matures with the formation of a collagen-based matrix [78], where the removal of myofibroblasts is controlled by unknown endogenous stop signals in order to restrain the fibrotic response [78]. However, a clear mechanistic view of phenotype and heterogeneity of cardiac fibroblasts in the process of fibrosis has yet to be fully established [77]. In terms of the underlying molecular mechanisms involved in the progression of fibrosis, several pathways, including the TGF- $\beta$, JNK/p38, $\mathrm{PI} 3 \mathrm{~K} / \mathrm{AKT}, \mathrm{WNT} / \beta$-catenin, and Ras-Raf- mitogenactivated protein kinase- (MEK-) extracellular signalactivated kinase (ERK) pathways, have been identified [79]. Involved in canonical fibrotic signaling, TGF- $\beta$ induces the nuclear translocation of the complex known as "mothers against decapentaplegic homolog," or SMAD complex promoting fibrosis. In noncanonical signaling, TGF- $\beta$ signaling induces SMAD-independent pathways, including the PI3K/AKT and mitogen-activated protein kinase (MAPK) pathways, nuclear factor kappa light chain enhancer of activated $\mathrm{B}$ cell $(\mathrm{NF}-\kappa \beta), \mathrm{RHO} / \mathrm{RACl}$, and CDC42 [75]. Interestingly, it has been suggested that, if supplied in a timely manner, $\mathrm{H}_{2} \mathrm{~S}$ can suppress TGF- $\beta 1$ induced transdifferentiation from fibroblasts to 
myofibroblasts via the inhibition of SMAD3 activation in human fibroblast cells [80].

\subsection{Antifibrosis Potential of $\mathrm{H}_{2} \mathrm{~S}$}

3.2.1. Myocardial Infarction. Extensive necrosis of cardiomyocytes in infarcted hearts not only triggers a strong inflammatory response but also induces interstitial and perivascular fibrosis due to geometrical, biomechanical, and biochemical changes in the uninjured ventricular wall [69]. During cardiac injury and hypertrophic remodeling, the production of inflammatory signaling molecules, such as tumor necrosis factor- $\alpha$ (TNF- $\alpha$ ), interleukin (IL)- $1 \beta$, and IL-6, can contribute to hypertrophic and fibrotic responses. Interestingly, ischemia causes a significant reduction in the levels of $\mathrm{H}_{2} \mathrm{~S}$ associated with decreased expression of CSE, which is an $\mathrm{H}_{2} \mathrm{~S}$-synthesizing enzyme under the control of the miRNA-30 family [16]. Moreover, it has been suggested that reduced plasma $\mathrm{H}_{2} \mathrm{~S}$ levels are correlated with the severity of coronary heart disease [81]. Similar to the cardioprotective role of NO [82-84], various signaling pathways from different types of exogenous $\mathrm{H}_{2} \mathrm{~S}$ may be involved in the suppression of MI-associated fibrosis (Table 1). These pathways include GSK- $3 \beta / \beta$-catenin [85], cGMP-PKG [86], Nrf2 [87-89], miRNA signaling pathways $[16,90,91]$, and the protection of mitochondria [92-95]. Although postconditioning only exerts cardioprotection in young hearts, exogenous $\mathrm{H}_{2} \mathrm{~S}$ restores postconditioning benefits by upregulating autophagy via the activation of the AMPK/mammalian target of rapamycin (mTOR) pathway in the aged hearts and cardiomyocytes [96]. It is unclear whether the signaling pathways identified share common contributors derived from $\mathrm{H}_{2} \mathrm{~S}$, or whether this is simply the result of experimental settings targeting different signaling pathways. Therefore, the identification of a unique contributor of $\mathrm{H}_{2} \mathrm{~S}$ involved in the suppression of MI-mediated myocardial fibrosis is necessary.

3.2.2. Hypertension. Hypertension increases oxidative stress, vascular inflammation, and vascular remodeling, such as in the case of fibrosis [97]. The antihypertensive effects of $\mathrm{H}_{2} \mathrm{~S}$, associated with its modulation of various levels of channel activity and cGMP-PKG pathways, may contribute to the suppression of fibrosis caused by hypertension [98-101]. As presented in Table $1, \mathrm{H}_{2} \mathrm{~S}$ supplementation under hypertensive conditions may suppress myocardial fibrosis via the modulation of several different signaling pathways. It is worth noting that $\mathrm{H}_{2} \mathrm{~S}$ can inhibit ACE via the binding of zinc ions to the active center of ACE [102]. It has been postulated that the $\mathrm{H}_{2} \mathrm{~S}$-mediated suppression of ACE may indirectly contribute to vasorelaxation and the suppression of the Ang-II-mediated transition of fibrosis. Alternatively, the suppression of inflammation [103] and the reduction of cardiomyocyte death from oxidative stress [104], as well as the activation of eNOS/NO pathway [105], are likely to have antifibrosis roles with regard to $\mathrm{H}_{2} \mathrm{~S}$ under hypertensive conditions. Interestingly, it has been noted that local delivery of $\mathrm{H}_{2} \mathrm{~S}$ can lower systemic blood pressure. For example, the intra-cerebroventricular (ICV) infusion of NaHS in both spontaneous and Ang-II-induced hypertensive rat models was found to decrease the mean arterial blood pressure and heart rate during ICV infusions [106]. Moreover, $\mathrm{H}_{2} \mathrm{~S}$ secreted from periadventitial adipose tissue has been previously found to contribute to blood pressure homeostasis [107].

3.2.3. Diabetes. The metabolic environment of diabetes, including hyperglycemia, hyperlipidemia, and oxidative stress, causes cardiomyocyte cell death. The early stages of diabetic remodeling of the heart are usually asymptomatic, such that myocardial changes mostly occur at the molecular level. In the middle stage of remodeling, progressive cardiomyocyte hypertrophy and myocardial fibrosis result in impaired ejection fraction [108]. In patients with diabetes, as well as in streptozotocin- (STZ-) treated rats, lowered circulating levels of $\mathrm{H}_{2} \mathrm{~S}$ due to the downregulated expression of $\mathrm{H}_{2} \mathrm{~S}$-synthesizing enzymes have been frequently found [109-111]. As depicted in Table 1, several underlying mechanisms of $\mathrm{H}_{2} \mathrm{~S}$ involve the suppression of myocardial fibrosis in diabetic rats via (1) the suppression of the TGF- $\beta 1 /$ SMAD3 pathway $[110,112,113]$ and canonical Wnt pathway [114], (2) the suppression of endoplasmic reticulum stress $[19,115]$, (3) the downregulation of the JAK/STAT signaling pathway [110], and (4) the regulation of autophagy [112, 116]. Although it has not yet been clearly elucidated, there is a possibility that $\mathrm{H}_{2} \mathrm{~S}$ may be involved in the modulation of ECM remodeling via miRNA or other transcription machinery affecting the expression of ECM-processing enzymes in diabetes. For example, $\mathrm{H}_{2} \mathrm{~S}$ has been found to attenuate fibrotic changes in diabetic kidneys via the downregulation of miRNA-194, which plays an important role in the modulation of proteins involved in collagen realignment [117].

3.2.4. Neurohormonal Overstimulation. The activation of the $\beta$-adrenergic nervous system and RAAS has been commonly found in fibrotic HF patients, and $\beta$-blockers and RAAS inhibitors have been suggested as a first-line treatment to correct the underlying cardiac dysfunction and reduce morbidity $[7,118]$. The overstimulation of $\beta$-adrenoceptor may result in the impairment of the negative modulation of $\mathrm{H}_{2} \mathrm{~S}$ on the $\beta$-adrenoceptor system, resulting in a calcium overload, leading to the impairment of cardiac contractility and, ultimately, to cardiomyocyte death [119]. Exogenous $\mathrm{H}_{2} \mathrm{~S}$ supplementation inhibits isoprenaline- (ISO-) induced cardiac hypertrophy depending on SIRT3, which is predominantly localized in the mitochondria, and may be associated with antioxidant properties [120]. Other signaling pathways, including reducing NADPH oxidase [121] or S-sulfhydration of $\mathrm{Ca}^{2+} /$ calmodulin-dependent protein kinase II [122], have been associated with the antifibrosis role of $\mathrm{H}_{2} \mathrm{~S}$ under conditions of $\beta$-adrenoceptor overstimulation. Mast cells will infiltrate into the heart at the site of inflammation and serve as a local source of renin in cardiovascular tissues. $\mathrm{H}_{2} \mathrm{~S}$ may benefit from the action of renin secreted from mast cells [123]. In view of hormone-associated myocardial fibrosis, the 
excessive generation of thyroxine from thyroid induces thyrotoxicosis and affects the cardiovascular system, resulting in the symptoms of hypertension, arrhythmia, and cardiac hypertrophy [124]. Under conditions of excessive thyroxine, $\mathrm{H}_{2} \mathrm{~S}$ may bolster rat myocardial fibrosis through the activation of autophagy mediated by the PI3K/AKT signaling pathway and via the downregulation of miRNA-21, miRNA-34a, and miRNA-214 expression [125].

\section{Summary and Perspectives}

Currently, strategies for the treatment of established HF are focused on relieving the symptoms and signs of $\mathrm{HF}$, such as treating edema, preventing hospital admission, and improving survival [6]. Myocardial fibrosis determines the clinical course of heart dysfunction and can eventually lead to heart failure. A substantial amount of research has been dedicated to the identification of HF target(s) to improve the diagnosis and treatment of fibrotic pathways with organ specificity. Myocardial fibrosis has many steps and usually involves several pathways. Complex networks of molecular signaling, including GSK-3 $\beta, \beta$-catenin, and TGF- $\beta 1 /$ SMAD3, have been implicated in the initiation, progression, and regression of myocardial fibrosis [1-5]. The targeting of collagen fibrillogenesis should be performed with caution as collagen turnover is a common process in most tissues whose effects can be detrimental [150]. Although TGF- $\beta 1$ is a central profibrogenic cytokine and a critical contributor during myocardial fibrosis, treatment with TGF- $\beta$ antibody has been found to result in an increased mortality rate and poor MIassociated ventricular remodeling in a mouse model [151]. Although SMAD3 and TNF- $\alpha$ signaling play a fundamental role in fibrosis progression, the targeting of SMAD3 and TNF- $\alpha$ antagonism has not yet been found to provide a successful antifibrosis outcome [151]. Based on the important role of Ang-II in the initiation of myocardial fibrosis, the antagonism of the angiotensin pathway via ACE inhibitors and angiotensin receptor antagonists is considered to be a useful approach for the management of fibrotic diseases. Recently, AMPK $\alpha$ activators (e.g., metformin) have been found to be a promising therapeutic target for fibrosis [152]. Myocardial fibrosis is not caused by a single profibrotic pathway but is rather associated with the activation of several profibrotic pathways, including immunological and molecular mechanisms [70]. It is also worth noting that a combined antifibrotic strategy, including inflammatory mediators, profibrotic cytokines, and epigenetic and cell and/or tissue intrinsic changes, has been suggested as a possible method for the successful treatment of myocardial fibrosis [7, 70].

As briefly addressed in this review, $\mathrm{H}_{2} \mathrm{~S}$ possesses antioxidant capacities and modulates various signaling pathways, including the activation of cGMP-PKG pathways, the posttranslational modification of proteins, metalbinding (including heme), and mitochondrial respiratory control [9]. In addition, $\mathrm{H}_{2} \mathrm{~S}$ may serve as a fine-tuner of mitochondrial homeostasis and the autophagic process in the physiology and pathophysiology of the cardiovascular system [153]. Moreover, $\mathrm{H}_{2} \mathrm{~S}$ is involved in antiapoptosis of cardiomyocytes, anti-inflammation, antihypertension, and other beneficial cardiovascular processes [154, 155]. As a timely response to energy stress, autophagy is a bulk degradation/recycling system that is tightly controlled by the homeostatic pathway in the cardiovascular system $[153,156]$. Despite the existence of conflicting opinions on the beneficial and harmful effects of autophagy, disturbances in the autophagic process have been found in various forms of $\mathrm{HF}$, including age-related cardiomyopathies [156] $\mathrm{H}_{2} \mathrm{~S}$ may be involved in the regulation of autophagy by either suppressing or enhancing the signaling pathways that contribute to the attenuation of myocardial fibrosis, as reviewed in a previous paper $[156,157]$. Although it is still currently under investigation, numerous findings have demonstrated that $\mathrm{H}_{2} \mathrm{~S}$ may be involved in the suppression of myocardial fibrosis caused by (1) myocardial infarction, (2) hypertension, (3) STZ-induced diabetes, and (4) the overstimulation of neurohormonal routes (Table 1). The signaling pathways mediated by $\mathrm{H}_{2} \mathrm{~S}$ may converge on the suppression of myocardial fibrosis that occurs as a result of various stresses, as shown in Figure 2 and Table 1. It is unclear whether target pathways modulated by the action of $\mathrm{H}_{2} \mathrm{~S}$ work independently of each other; however, it is most important to determine whether they allow for the merging of multiple pathways into a single antifibrosis signaling cascade. Versatile mechanisms and signaling pathways triggered by $\mathrm{H}_{2} \mathrm{~S}$ have already been identified, as briefly shown in this review. In this context, it appears that $\mathrm{H}_{2} \mathrm{~S}$ is emerging as a new type of myocardial fibrosis suppressor. However, it is necessary to identify the molecular target or specific signaling pathway that is under the control of $\mathrm{H}_{2} \mathrm{~S}$ in a direct and specific manner during myocardial fibrosis. It remains to be clearly established whether $\mathrm{H}_{2} \mathrm{~S}$ can directly control the cells involved in fibrosis (e.g., cardiomyocytes, fibroblasts, and inflammatory cells) and ECM deposition.

The advances being made in $\mathrm{H}_{2} \mathrm{~S}$ biology are a promising tool for the future development of medicines for the treatment of myocardial fibrosis based on $\mathrm{H}_{2} \mathrm{~S}$, as well as multitarget molecules able to release $\mathrm{H}_{2} \mathrm{~S}$ [158]. There is currently a lack of fibrosis-specific biomarkers that can be used to determine the stage and grade of myocardial fibrosis, as well as for the identification of patients who may benefit from a specific type of therapy. In addition to the development of new techniques for evaluating the stage and/or severity of myocardial fibrosis [159], a new strategy for reversing preexisting fibrosis using $\mathrm{H}_{2} \mathrm{~S}$ could be a valuable approach. Moreover, the potential of $\mathrm{H}_{2} \mathrm{~S}$ in preventing or repairing cardiomyocyte loss via the stimulation of cardiac stem cells or transdifferentiation from noncardiomyocytes to cardiomyocytes needs to be critically evaluated in future studies [160]. It is worth mentioning that $\mathrm{H}_{2} \mathrm{~S}$ can have serious and toxic effects at high concentrations or high release rates, including sudden unconsciousness and death $[14,161]$. Therefore, the optimal concentration or dose of $\mathrm{H}_{2} \mathrm{~S}$ for the desired antifibrosis effect needs to be critically examined. Additionally, for the therapeutic potential of $\mathrm{H}_{2} \mathrm{~S}$, pharmacological agents that generate or release $\mathrm{H}_{2} \mathrm{~S}$ need to be adequately harnessed for the delivery of physiologically relevant concentrations in a safe manner. Considering that myocardial fibrosis is a long- 
term consequence of heart disease, the study of dietary supplements that are able to supply $\mathrm{H}_{2} \mathrm{~S}$ safely or boost $\mathrm{H}_{2} \mathrm{~S}$ synthesis is needed for the management of myocardial fibrosis. The long-term consequences and clinical benefits of $\mathrm{H}_{2} \mathrm{~S}$ against myocardial fibrosis should also be investigated in the future. In addition, the study of the $\mathrm{H}_{2} \mathrm{~S}$-mediated the study of the $\mathrm{H}_{2} \mathrm{~S}$-mediated reversal of myocardial fibrosis could prove to be advantageous in clinical studies.

\section{Conflicts of Interest}

The authors declare that there are no conflicts of interest.

\section{Authors' Contributions}

Se Chan Kang and Eun-Hwa Sohn equally contributed to this work.

\section{Acknowledgments}

This work was supported by the Basic Science Research Program through the National Research Foundation of Korea (NRF) funded by the Ministry of Education, Science, and Technology (No. 2015R1D1A3A01015596). The authors apologize for the vast number of outstanding publications that could not be cited owing to space limitations.

\section{References}

[1] A. Piek, R. A. de Boer, and H. H. W. Silljé, "The fibrosis-cell death axis in heart failure," Heart Failure Reviews, vol. 21, no. 2, pp. 199-211, 2016.

[2] M. L. Urban, L. Manenti, and A. Vaglio, "Fibrosis-a common pathway to organ injury and failure," The New England Journal of Medicine, vol. 373, no. 1, pp. 95-96, 2015.

[3] A. M. Segura, O. H. Frazier, and L. M. Buja, "Fibrosis and heart failure," Heart Failure Reviews, vol. 19, no. 2, pp. 173$185,2014$.

[4] R. Weiskirchen, S. Weiskirchen, and F. Tacke, "Organ and tissue fibrosis: molecular signals, cellular mechanisms and translational implications," Molecular Aspects of Medicine, vol. 65, pp. 2-15, 2019.

[5] J. Wu, W. Guo, S. Z. Lin et al., "Gp130-mediated STAT3 activation by S-propargyl-cysteine, an endogenous hydrogen sulfide initiator, prevents doxorubicin-induced cardiotoxicity," Cell Death \& Disease, vol. 7, no. 8, pp. e2339e2339, 2016.

[6] J. J. McMurray, S. Adamopoulos, S. D. Anker et al., "ESC guidelines for the diagnosis and treatment of acute and chronic heart failure 2012: the task force for the diagnosis and treatment of acute and chronic heart failure 2012 of the European Society of Cardiology. Developed in collaboration with the heart failure association (HFA) of the ESC," European Heart Journal, vol. 33, no. 14, pp. 1787-1847, 2012.

[7] M. N. Jameel and J. Zhang, "Heart failure management: the present and the future," Antioxidants \& Redox Signaling, vol. 11, no. 8, pp. 1989-2010, 2009.

[8] R. Wang, "Gasotransmitters: growing pains and joys," Trends in Biochemical Sciences, vol. 39, no. 5, pp. 227-232, 2014.

[9] S. R. Lee, B. Nilius, and J. Han, "Gaseous signaling molecules in cardiovascular function: from mechanisms to clinical translation," Reviews of Physiology, Biochemistry and Pharmacology, vol. 174, pp. 81-156, 2018.

[10] R. Wang, "Two's company, three's a crowd: can H2S be the third endogenous gaseous transmitter?," FASEB Journal, vol. 16, no. 13, pp. 1792-1798, 2002.

[11] L. L. Pan, M. Qin, X. H. Liu, and Y. Z. Zhu, "The role of hydrogen sulfide on cardiovascular homeostasis: an overview with update on immunomodulation," Frontiers in Pharmacology, vol. 8, 2017.

[12] B. L. Predmore, D. J. Lefer, and G. Gojon, "Hydrogen sulfide in biochemistry and medicine," Antioxidants \& Redox Signaling, vol. 17, no. 1, pp. 119-140, 2012.

[13] J. W. Calvert, W. A. Coetzee, and D. J. Lefer, "Novel insights into hydrogen sulfide-mediated cytoprotection," Antioxidants \& Redox Signaling, vol. 12, no. 10, pp. 1203-1217, 2010.

[14] G. Szabó, G. Veres, T. Radovits et al., "Cardioprotective effects of hydrogen sulfide," Nitric Oxide, vol. 25, no. 2, pp. 201-210, 2011.

[15] A. Deb and E. Ubil, "Cardiac fibroblast in development and wound healing," Journal of Molecular and Cellular Cardiology, vol. 70, pp. 47-55, 2014.

[16] Y. Shen, Z. Shen, L. Miao et al., "miRNA-30 family inhibition protects against cardiac ischemic injury by regulating cystathionine- $\gamma$-lyase expression," Antioxidants \& Redox Signaling, vol. 22, no. 3, pp. 224-240, 2015.

[17] L. Zhang, Y. Wang, Y. Li et al., "Hydrogen sulfide $\left(\mathrm{H}_{2} \mathrm{~S}\right)$ releasing compounds: therapeutic potential in cardiovascular diseases," Frontiers in Pharmacology, vol. 9, article 1066, 2018.

[18] R. Guo, Z. Wu, J. Jiang et al., "New mechanism of lipotoxicity in diabetic cardiomyopathy: deficiency of endogenous $\mathrm{H}_{2} \mathrm{~S}$ production and ER stress," Mechanisms of Ageing and Development, vol. 162, pp. 46-52, 2017.

[19] L. A. Barr, Y. Shimizu, J. P. Lambert, C. K. Nicholson, and J. W. Calvert, "Hydrogen sulfide attenuates high fat diet-induced cardiac dysfunction via the suppression of endoplasmic reticulum stress," Nitric Oxide, vol. 46, pp. 145-156, 2015.

[20] U. Sen, P. K. Mishra, N. Tyagi, and S. C. Tyagi, "Homocysteine to hydrogen sulfide or hypertension," Cell Biochemistry and Biophysics, vol. 57, no. 2-3, pp. 49-58, 2010.

[21] M. Racine, M. Fu, T. Shuang et al., "Reversal of Sp1 transactivation and TGF $\beta 1 /$ SMAD1 signaling by $\mathrm{H}_{2} \mathrm{~S}$ prevent nickel-induced fibroblast activation," Toxicology and Applied Pharmacology, vol. 356, pp. 25-35, 2018.

[22] M. M. Cortese-Krott, G. G. C. Kuhnle, A. Dyson et al., "Key bioactive reaction products of the $\mathrm{NO} / \mathrm{H}_{2} \mathrm{~S}$ interaction are S/N-hybrid species, polysulfides, and nitroxyl," Proceedings of the National Academy of Sciences of the United States of America, vol. 112, no. 34, pp. E4651E4660, 2015.

[23] J. Beltowski, "Hydrogen sulfide in pharmacology and medicine - An update," Pharmacological Reports, vol. 67, no. 3, pp. 647-658, 2015.

[24] S. Yuan, S. Pardue, X. Shen, J. S. Alexander, A. W. Orr, and C. G. Kevil, "Hydrogen sulfide metabolism regulates endothelial solute barrier function," Redox Biology, vol. 9, pp. 157-166, 2016.

[25] B. Geng, J. Yang, Y. Qi et al., " $\mathrm{H}_{2}$ S generated by heart in rat and its effects on cardiac function," Biochemical and Biophysical Research Communications, vol. 313, no. 2, pp. 362-368, 2004. 
[26] W. Zhao, J. Zhang, Y. Lu, and R. Wang, "The vasorelaxant effect of $\mathrm{H}_{2} \mathrm{~S}$ as a novel endogenous gaseous $\mathrm{K}_{\mathrm{ATP}}$ channel opener," EMBO Journal, vol. 20, no. 21, pp. 6008-6016, 2001.

[27] R. Hosoki, N. Matsuki, and H. Kimura, "The possible role of hydrogen sulfide as an endogenous smooth muscle relaxant in synergy with nitric oxide," Biochemical and Biophysical Research Communications, vol. 237, no. 3, pp. 527-531, 1997.

[28] J. Beltowski and A. Jamroz-Wisniewska, "Hydrogen sulfide and endothelium-dependent vasorelaxation," Molecules, vol. 19, no. 12, pp. 21183-21199, 2014.

[29] Y. Enokido, E. Suzuki, K. Iwasawa, K. Namekata, H. Okazawa, and H. Kimura, "Cystathionine beta-synthase, a key enzyme for homocysteine metabolism, is preferentially expressed in the radial glia/astrocyte lineage of developing mouse CNS," FASEB Journal, vol. 19, no. 13, pp. 18541856, 2005.

[30] J. I. Toohey, "Sulfur signaling: is the agent sulfide or sulfane?," Analytical Biochemistry, vol. 413, no. 1, pp. 1-7, 2011.

[31] J. Yang, P. Minkler, D. Grove et al., "Non-enzymatic hydrogen sulfide production from cysteine in blood is catalyzed by iron and vitamin $\mathrm{B}_{6}$," Communications Biology, vol. 2, no. 1, article 194, 2019.

[32] M. L. Morrison, J. E. Blackwood, S. L. Lockett, A. Iwata, R. K. Winn, and M. B. Roth, "Surviving blood loss using hydrogen sulfide," The Journal of Trauma, vol. 65, no. 1, pp. 183-188, 2008.

[33] P. Dorsey, C. Keel, M. Klavens, and W. J. Hellstrom, "Phosphodiesterase type 5 (PDE5) inhibitors for the treatment of erectile dysfunction," Expert Opinion on Pharmacotherapy, vol. 11, no. 7, pp. 1109-1122, 2010.

[34] K. U. Tüfekci, R. L. J. Meuwissen, and Ş. Genç, "The Role of Micro RNAs in Biological Processes," in miRNomics: microRNA biology and computational analysis, M. Yousef and J. Allmer, Eds., pp. 15-31, Humana Press, Totowa, NJ, USA, 2014.

[35] J. Wilinski, E. Somogyi, M. Góralska, B. Wiliński, and D. Czarnecka, "Ramipril enhances the endogenous hydrogen sulfide tissue concentration in mouse heart and brain," Folia Medica Cracoviensia, vol. 49, no. 3-4, pp. 123-130, 2008.

[36] Y. Xu, H.-P. Du, J. Li et al., "Statins upregulate cystathionine $\gamma$-lyase transcription and $\mathrm{H}_{2} \mathrm{~S}$ generation via activating Akt signaling in macrophage," Pharmacological Research, vol. 87, pp. 18-25, 2014.

[37] B. Wilinski, J. Wiliński, E. Somogyi, J. Piotrowska, and M. Góralska, "Amlodipine affects endogenous hydrogen sulfide tissue concentrations in different mouse organs," Folia Medica Cracoviensia, vol. 51, no. 1-4, pp. 29-35, 2011.

[38] W. Bogdan, W. Jerzy, S. Eugeniusz, P. Joanna, and G. Marta, "Digoxin increases hydrogen sulfide concentrations in brain, heart and kidney tissues in mice," Pharmacological Reports, vol. 63, no. 5, pp. 1243-1247, 2011.

[39] B. Wilinski, J. Wilinski, E. Somogyi, J. Piotrowska, and W. Opoka, "Vitamin D3 (cholecalciferol) boosts hydrogen sulfide tissue concentrations in heart and other mouse organs," Folia Biologica, vol. 60, no. 3, pp. 243-247, 2012.

[40] A. Bilska, M. Iciek, I. Kwiecień et al., "Effects of aspirin on the levels of hydrogen sulfide and sulfane sulfur in mouse tissues," Pharmacological Reports, vol. 62, no. 2, pp. 304-310, 2010.

[41] J. Beltowski and A. Jamroz-Wisniewska, "Modulation of h(2) s metabolism by statins: a new aspect of cardiovascular phar- macology," Antioxidants \& Redox Signaling, vol. 17, no. 1, pp. 81-94, 2012.

[42] H. Kimura, "Hydrogen sulfide and polysulfides as biological mediators," Molecules, vol. 19, no. 10, pp. 16146-16157, 2014.

[43] G. A. Benavides, G. L. Squadrito, R. W. Mills et al., "Hydrogen sulfide mediates the vasoactivity of garlic," Proceedings of the National Academy of Sciences of the United States of America, vol. 104, no. 46, pp. 17977-17982, 2007.

[44] K. Okubo, M. Matsumura, Y. Kawaishi et al., "Hydrogen sulfide-induced mechanical hyperalgesia and allodynia require activation of both Cav3.2 and TRPA1 channels in mice," British Journal of Pharmacology, vol. 166, no. 5, pp. 1738-1743, 2012.

[45] D. J. Polhemus and D. J. Lefer, "Emergence of hydrogen sulfide as an endogenous gaseous signaling molecule in cardiovascular disease," Circulation Research, vol. 114, no. 4, pp. 730-737, 2014.

[46] T. Corsello, N. Komaravelli, and A. Casola, "Role of hydrogen sulfide in NRF2- and sirtuin-dependent maintenance of cellular redox balance," Antioxidants, vol. 7, no. 10, p. 129, 2018.

[47] Y. Kimura and H. Kimura, "Hydrogen sulfide protects neurons from oxidative stress," FASEB Journal, vol. 18, no. 10, pp. 1165-1167, 2004.

[48] N. J. Alp and K. M. Channon, "Regulation of endothelial nitric oxide synthase by tetrahydrobiopterin in vascular disease," Arteriosclerosis, Thrombosis, and Vascular Biology, vol. 24, no. 3, pp. 413-420, 2004.

[49] J. D. Raffetto and R. A. Khalil, "Matrix metalloproteinases and their inhibitors in vascular remodeling and vascular disease," Biochemical Pharmacology, vol. 75, no. 2, pp. 346-359, 2008.

[50] N. Takahashi, D. Kozai, and Y. Mori, "TRP channels: sensors and transducers of gasotransmitter signals," Frontiers in Physiology, vol. 3, p. 324, 2012.

[51] A. K. Mustafa, M. M. Gadalla, and S. H. Snyder, "Signaling by gasotransmitters," Science signaling, vol. 2, no. 68, article re2, 2009.

[52] M. T. Nelp, V. Zheng, K. M. Davis, K. J. E. Stiefel, and J. T. Groves, "Potent activation of indoleamine 2,3-dioxygenase by polysulfides," Journal of the American Chemical Society, vol. 141, no. 38, pp. 15288-15300, 2019.

[53] A. K. Mustafa, M. M. Gadalla, N. Sen et al., "H2S signals through protein S-sulfhydration," Science signaling, vol. 2, no. 96, article ra72, 2009.

[54] K. Módis, Y. J. Ju, A. Ahmad et al., "S-Sulfhydration of ATP synthase by hydrogen sulfide stimulates mitochondrial bioenergetics," Pharmacological Research, vol. 113, Part A, pp. 116-124, 2016.

[55] N. Sen, "Functional and molecular insights of hydrogen sulfide signaling and protein Sulfhydration," Journal of Molecular Biology, vol. 429, no. 4, pp. 543-561, 2017.

[56] P. Manna and S. K. Jain, "Hydrogen sulfide and L-cysteine increase phosphatidylinositol 3,4,5-trisphosphate (PIP3) and glucose utilization by inhibiting phosphatase and tensin homolog (PTEN) protein and activating phosphoinositide 3kinase $(\mathrm{PI} 3 \mathrm{~K}) /$ serine/threonine protein kinase $(\mathrm{AKT}) /$ protein kinase $\mathrm{C} \zeta / \lambda(\mathrm{PKC} \zeta / \lambda)$ in 3T3l1 adipocytes," The Journal of Biological Chemistry, vol. 286, no. 46, pp. 39848-39859, 2011.

[57] Y. Sun, Y. Huang, W. Yu et al., "Sulfhydration-associated phosphodiesterase 5A dimerization mediates vasorelaxant effect of hydrogen sulfide," Oncotarget, vol. 8, no. 19, pp. 31888-31900, 2017. 
[58] T. D. Baird and R. C. Wek, "Eukaryotic initiation factor 2 phosphorylation and translational control in metabolism," Advances in Nutrition, vol. 3, no. 3, pp. 307-321, 2012.

[59] V. Yadav, X. H. Gao, B. Willard, M. Hatzoglou, R. Banerjee, and O. Kabil, "Hydrogen sulfide modulates eukaryotic translation initiation factor $2 \alpha$ (eIF $2 \alpha$ ) phosphorylation status in the integrated stress-response pathway," Journal of Biological Chemistry, vol. 292, no. 32, pp. 13143-13153, 2017.

[60] L. Li, D. Liu, D. Bu et al., "Brg1-dependent epigenetic control of vascular smooth muscle cell proliferation by hydrogen sulfide," Biochimica et Biophysica Acta (BBA) - Molecular Cell Research, vol. 1833, no. 6, pp. 1347-1355, 2013.

[61] Y. Sun, Z. Tian, N. Liu et al., "Exogenous $\mathrm{H}_{2} \mathrm{~S}$ switches cardiac energy substrate metabolism by regulating SIRT3 expression in $\mathrm{db} / \mathrm{db}$ mice," Journal of Molecular Medicine, vol. 96, no. 3-4, pp. 281-299, 2018.

[62] D. F. Dai, P. S. Rabinovitch, and Z. Ungvari, "Mitochondria and cardiovascular aging," Circulation Research, vol. 110, no. 8, pp. 1109-1124, 2012.

[63] M. U. Khan, Y. Cheema, A. U. Shahbaz et al., "Mitochondria play a central role in nonischemic cardiomyocyte necrosis: common to acute and chronic stressor states," Pflügers Archiv-European Journal of Physiology, vol. 464, no. 1, pp. 123-131, 2012.

[64] S. Li and G. Yang, "Hydrogen sulfide maintains mitochondrial DNA replication via demethylation of TFAM," Antioxidants \& Redox Signaling, vol. 23, no. 7, pp. 630-642, 2015.

[65] Y. Shimizu, R. Polavarapu, K. L. Eskla et al., "Hydrogen sulfide regulates cardiac mitochondrial biogenesis via the activation of AMPK," Journal of Molecular and Cellular Cardiology, vol. 116, pp. 29-40, 2018.

[66] D. Fan, A. Takawale, J. Lee, and Z. Kassiri, "Cardiac fibroblasts, fibrosis and extracellular matrix remodeling in heart disease," Fibrogenesis Tissue Repair, vol. 5, no. 1, p. 15, 2012.

[67] P. Zhou and W. T. Pu, "Recounting cardiac cellular composition," Circulation Research, vol. 118, no. 3, pp. 368-370, 2016.

[68] P. Pakshir and B. Hinz, "The big five in fibrosis: macrophages, myofibroblasts, matrix, mechanics, and miscommunication," Matrix Biology, vol. 68-69, pp. 81-93, 2018.

[69] V. Talman and H. Ruskoaho, "Cardiac fibrosis in myocardial infarction-from repair and remodeling to regeneration," Cell and Tissue Research, vol. 365, no. 3, pp. 563-581, 2016.

[70] T. A. Wynn and T. R. Ramalingam, "Mechanisms of fibrosis: therapeutic translation for fibrotic disease," Nature Medicine, vol. 18, no. 7, pp. 1028-1040, 2012.

[71] S. Rosenkranz, "TGF- $\beta_{1}$ and angiotensin networking in cardiac remodeling," Cardiovascular Research, vol. 63, no. 3, pp. 423-432, 2004.

[72] S. Psarras, D. Beis, S. Nikouli, M. Tsikitis, and Y. Capetanaki, "Three in a box: understanding cardiomyocyte, fibroblast, and innate immune cell interactions to orchestrate cardiac repair processes," Frontiers in Cardiovascular Medicine, vol. 6, p. 32, 2019.

[73] J. G. Travers, F. A. Kamal, J. Robbins, K. E. Yutzey, and B. C. Blaxall, "Cardiac fibrosis: the fibroblast awakens," Circulation Research, vol. 118, no. 6, pp. 1021-1040, 2016.

[74] P. Kong, P. Christia, and N. G. Frangogiannis, "The pathogenesis of cardiac fibrosis," Cellular and Molecular Life Sciences, vol. 71, no. 4, pp. 549-574, 2014.

[75] Z. G. Ma, Y. P. Yuan, H. M. Wu, X. Zhang, and Q. Z. Tang, "Cardiac fibrosis: new insights into the pathogenesis," Inter- national Journal of Biological Sciences, vol. 14, no. 12, pp. 1645-1657, 2018.

[76] K. C. Flanders, "Smad3 as a mediator of the fibrotic response," International Journal of Experimental Pathology, vol. 85, no. 2, pp. 47-64, 2004.

[77] Y. Ma, R. P. Iyer, M. Jung, M. P. Czubryt, and M. L. Lindsey, "Cardiac fibroblast activation post-myocardial infarction: current knowledge gaps," Trends in Pharmacological Sciences, vol. 38, no. 5, pp. 448-458, 2017.

[78] A. V. Shinde and N. G. Frangogiannis, "Fibroblasts in myocardial infarction: a role in inflammation and repair," Journal of Molecular and Cellular Cardiology, vol. 70, pp. 74-82, 2014.

[79] C. J. Li, C. S. Chen, G. T. Yiang, A. P.-Y. Tsai, W.-T. Liao, and M.-Y. Wu, "Advanced evolution of pathogenesis concepts in cardiomyopathies," Journal of Clinical Medicine, vol. 8, no. 4, p. 520, 2019.

[80] Y. Zhang, J. Wang, H. Li et al., "Hydrogen sulfide suppresses transforming growth factor- $\beta 1$-induced differentiation of human cardiac fibroblasts into myofibroblasts," Science China Life Sciences, vol. 58, no. 11, pp. 11261134, 2015.

[81] H. L. Jiang, H. C. Wu, Z. L. Li, B. Geng, and C. S. Tang, "Changes of the new gaseous transmitter H2S in patients with coronary heart disease," Di Yi Jun Yi Da Xue Xue Bao, vol. 25, no. 8, pp. 951-954, 2005.

[82] M. V. Cohen, X. M. Yang, and J. M. Downey, "Nitric oxide is a preconditioning mimetic and cardioprotectant and is the basis of many available infarct-sparing strategies," Cardiovascular Research, vol. 70, no. 2, pp. 231239, 2006

[83] P. Pagliaro, D. Gattullo, R. Rastaldo, and G. Losano, "Involvement of nitric oxide in ischemic preconditioning," Italian Heart Journal, vol. 2, no. 9, pp. 660-668, 2001.

[84] S. R. Lee and J. Han, "Mitochondrial metabolic inhibition and cardioprotection," Korean Circulation Journal, vol. 47, no. 2, pp. 168-170, 2017.

[85] N. Ge, C. Liu, G. Li et al., "Hydrosulfide attenuates acute myocardial ischemic injury through the glycogen synthase kinase$3 \beta / \beta$-catenin signaling pathway," International Journal of Molecular Medicine, vol. 37, no. 5, pp. 1281-1289, 2016.

[86] D. Wu, Q. Hu, Y. Xiong, D. Zhu, Y. Mao, and Y. Z. Zhu, "Novel $\mathrm{H}_{2} \mathrm{~S}-\mathrm{NO}$ hybrid molecule (ZYZ-803) promoted synergistic effects against heart failure," Redox Biology, vol. 15, pp. 243-252, 2018.

[87] Y. Shimizu, C. K. Nicholson, J. P. Lambert et al., "Sodium sulfide attenuates ischemic-induced heart failure by enhancing proteasomal function in an Nrf2-dependent manner," Circulation: Heart Failure, vol. 9, no. 4, article e002368, 2016.

[88] L. Xie, Y. Gu, M. Wen et al., "Hydrogen sulfide induces Keap1 $\mathrm{S}$-sulfhydration and suppresses diabetes-accelerated atherosclerosis via Nrf2 activation," Diabetes, vol. 65, no. 10, pp. 3171-3184, 2016.

[89] C. Y. Tsai, C. C. Wang, T. Y. Lai et al., "Antioxidant effects of diallyl trisulfide on high glucose-induced apoptosis are mediated by the PI3K/Akt-dependent activation of Nrf2 in cardiomyocytes," International Journal of Cardiology, vol. 168, no. 2, pp. 1286-1297, 2013.

[90] A. M. Rodriguez and V. P. Yin, "Emerging roles for immune cells and microRNAs in modulating the response to cardiac 
injury," Journal of Cardiovascular Development and Disease, vol. 6, no. 1, p. 5, 2019.

[91] S. Toldo, A. Das, E. Mezzaroma et al., "Induction of microRNA-21 with exogenous hydrogen sulfide attenuates myocardial ischemic and inflammatory injury in mice," Circulation: Cardiovascular Genetics, vol. 7, no. 3, pp. 311-320, 2014.

[92] H. Li, C. Zhang, W. Sun et al., "Exogenous hydrogen sulfide restores cardioprotection of ischemic post-conditioning via inhibition of mPTP opening in the aging cardiomyocytes," Cell \& Bioscience, vol. 5, no. 1, p. 43, 2015.

[93] A. Chatzianastasiou, S. I. Bibli, I. Andreadou et al., "Cardioprotection by $\mathrm{H} 2 \mathrm{~S}$ donors: nitric oxide-dependent and independent mechanisms," Journal of Pharmacology and Experimental Therapeutics, vol. 358, no. 3, pp. 431-440, 2016.

[94] Q. G. Karwi, J. Bornbaum, K. Boengler et al., “AP39, a mitochondria-targeting hydrogen sulfide $\left(\mathrm{H}_{2} \mathrm{~S}\right)$ donor, protects against myocardial reperfusion injury independently of salvage kinase signalling," British Journal of Pharmacology, vol. 174, no. 4, pp. 287-301, 2017.

[95] J. W. Elrod, J. W. Calvert, J. Morrison et al., "Hydrogen sulfide attenuates myocardial ischemia-reperfusion injury by preservation of mitochondrial function," Proceedings of the National Academy of Sciences of the United States of America, vol. 104, no. 39, pp. 15560-15565, 2007.

[96] J. Chen, J. Gao, W. Sun et al., "Involvement of exogenous $\mathrm{H}_{2} \mathrm{~S}$ in recovery of cardioprotection from ischemic postconditioning via increase of autophagy in the aged hearts," International Journal of Cardiology, vol. 220, pp. 681-692, 2016.

[97] L. Rochette, Y. Cottin, M. Zeller, and C. Vergely, "Carbon monoxide: mechanisms of action and potential clinical implications," Pharmacology \& Therapeutics, vol. 137, no. 2, pp. 133-152, 2013.

[98] G. Meng, Y. Ma, L. Xie, A. Ferro, and Y. Ji, "Emerging role of hydrogen sulfide in hypertension and related cardiovascular diseases," British Journal of Pharmacology, vol. 172, no. 23, pp. 5501-5511, 2015.

[99] P. M. Snijder, A. R. Frenay, R. A. de Boer et al., "Exogenous administration of thiosulfate, a donor of hydrogen sulfide, attenuates angiotensin II-induced hypertensive heart disease in rats," British Journal of Pharmacology, vol. 172, no. 6, pp. 1494-1504, 2015.

[100] S. Cacanyiova, A. Berenyiova, F. Kristek, M. Drobna, K. Ondrias, and M. Grman, "The adaptive role of nitric oxide and hydrogen sulphide in vasoactive responses of thoracic aorta is triggered already in young spontaneously hypertensive rats," Journal of Physiology and Pharmacology, vol. 67, no. 4, pp. 501-512, 2016.

[101] L. Tomasova, L. Dobrowolski, H. Jurkowska et al., "Intracolonic hydrogen sulfide lowers blood pressure in rats," Nitric Oxide, vol. 60, pp. 50-58, 2016.

[102] H. Laggner, M. Hermann, H. Esterbauer et al., "The novel gaseous vasorelaxant hydrogen sulfide inhibits angiotensinconverting enzyme activity of endothelial cells," Journal of Hypertension, vol. 25, no. 10, pp. 2100-2104, 2007.

[103] T. Wu, H. Li, B. Wu et al., "Hydrogen sulfide reduces recruitment of CD $11 b^{+}$DG Gr- $1^{+}$DG cells in mice with myocardial infarction," Cell Transplantation, vol. 26, no. 5, pp. 753764, 2017.
[104] C. Huang, J. Kan, X. Liu et al., "Cardioprotective effects of a novel hydrogen sulfide agent-controlled release formulation of S-propargyl-cysteine on heart failure rats and molecular mechanisms," PLoS One, vol. 8, no. 7, pp. e69205-e69205, 2013.

[105] S. Jin, X. Teng, L. Xiao et al., "Hydrogen sulfide ameliorated L-NAME-induced hypertensive heart disease by the Akt/eNOS/NO pathway," Experimental Biology and Medicine, vol. 242, no. 18, pp. 1831-1841, 2017.

[106] M. Sikora, A. Drapala, and M. Ufnal, "Exogenous hydrogen sulfide causes different hemodynamic effects in normotensive and hypertensive rats via neurogenic mechanisms," Pharmacological Reports, vol. 66, no. 5, pp. 751-758, 2014.

[107] L. Fang, J. Zhao, Y. Chen et al., "Hydrogen sulfide derived from periadventitial adipose tissue is a vasodilator," Journal of Hypertension, vol. 27, no. 11, pp. 2174-2185, 2009.

[108] J. M. Pappachan, G. I. Varughese, R. Sriraman, and G. Arunagirinathan, "Diabetic cardiomyopathy: pathophysiology, diagnostic evaluation and management," World Journal of Diabetes, vol. 4, no. 5, pp. 177-189, 2013.

[109] S. K. Jain, R. Bull, J. L. Rains et al., "Low levels of hydrogen sulfide in the blood of diabetes patients and streptozotocin-treated rats causes vascular inflammation?," Antioxidants \& Redox Signaling, vol. 12, no. 11, pp. 1333-1337, 2010.

[110] M. Liu, Y. Li, B. Liang et al., "Hydrogen sulfide attenuates myocardial fibrosis in diabetic rats through the JAK/STAT signaling pathway," International Journal of Molecular Medicine, vol. 41, no. 4, pp. 1867-1876, 2018.

[111] S. Jin, S. X. Pu, C. L. Hou et al., "Cardiac $\mathrm{H}_{2} \mathrm{~S}$ generation is reduced in ageing diabetic mice," Oxidative Medicine and Cellular Longevity, vol. 2015, Article ID 758358, 14 pages, 2015.

[112] F. Yang, L. Zhang, Z. Gao et al., "Exogenous H2S protects against diabetic cardiomyopathy by activating autophagy via the AMPK/mTOR pathway," Cellular Physiology and Biochemistry, vol. 43, no. 3, pp. 11681187, 2017.

[113] T. Xiao, O. Zeng, J. Luo, Z. Wu, F. Li, and J. Yang, "Effects of hydrogen sulfide on myocardial fibrosis in diabetic rats: changes in matrix metalloproteinases parameters," Bio-Medical Materials and Engineering, vol. 26, no. s1, pp. S2033S2039, 2015.

[114] R. Yang, Q. Jia, S. F. Ma, Y. Wang, S. Mehmood, and Y. Chen, "Exogenous H2S mitigates myocardial fibrosis in diabetic rats through suppression of the canonical Wnt pathway," International Journal of Molecular Medicine, vol. 44, no. 2, pp. 549-558, 2019.

[115] F. Li, J. Luo, Z. Wu et al., "Hydrogen sulfide exhibits cardioprotective effects by decreasing endoplasmic reticulum stress in a diabetic cardiomyopathy rat model," Molecular Medicine Reports, vol. 14, no. 1, pp. 865-873, 2016.

[116] T. Xiao, J. Luo, Z. Wu, F. Li, O. Zeng, and J. Yang, "Effects of hydrogen sulfide on myocardial fibrosis and PI3K/AKT1regulated autophagy in diabetic rats," Molecular Medicine Reports, vol. 13, no. 2, pp. 1765-1773, 2016.

[117] A. John, S. Kundu, S. Pushpakumar et al., "GYY4137, a hydrogen sulfide donor modulates miR194-dependent collagen realignment in diabetic kidney," Scientific Reports, vol. 7, no. 1, article 10924, 2017. 
[118] N. Zhang, W. Y. Wei, L. L. Li, C. Hu, and Q.-Z. Tang, "Therapeutic potential of polyphenols in cardiac fibrosis," Frontiers in Pharmacology, vol. 9, p. 122, 2018.

[119] Q. C. Yong, T. T. Pan, L. F. Hu, and J. S. Bian, "Negative regulation of $\beta$-adrenergic function by hydrogen sulphide in the rat hearts," Journal of Molecular and Cellular Cardiology, vol. 44, no. 4, pp. 701-710, 2008.

[120] J. Zhang, J. Yu, Y. Chen et al., "Exogenous hydrogen sulfide supplement attenuates isoproterenol-induced myocardial hypertrophy in a sirtuin 3-dependent manner," Oxidative Medicine and Cellular Longevity, vol. 2018, 17 pages, 2018.

[121] Z. Zhang, S. Jin, X. Teng, X. Duan, Y. Chen, and Y. Wu, "Hydrogen sulfide attenuates cardiac injury in takotsubo cardiomyopathy by alleviating oxidative stress," Nitric Oxide, vol. 67, pp. 10-25, 2017.

[122] D. Wu, Q. Hu, B. Tan, P. Rose, D. Zhu, and Y. Z. Zhu, "Amelioration of mitochondrial dysfunction in heart failure through $S$-sulfhydration of $\mathrm{Ca}^{2+} /$ calmodulin-dependent protein kinase II," Redox Biology, vol. 19, pp. 250-262, 2018.

[123] A. C. Reid, J. A. Brazin, C. Morrey, R. B. Silver, and R. Levi, "Targeting cardiac mast cells: pharmacological modulation of the local renin-angiotensin system," Current Pharmaceutical Design, vol. 17, no. 34, pp. 3744-3752, 2011.

[124] F. Vargas, J. M. Moreno, I. Rodriguez-Gómez et al., "Vascular and renal function in experimental thyroid disorders," European Journal of Endocrinology, vol. 154, no. 2, pp. 197-212, 2006.

[125] M. Liu, Z. Li, B. Liang et al., "Hydrogen sulfide ameliorates rat myocardial fibrosis induced by thyroxine through PI3K/AKT signaling pathway," Endocrine Journal, vol. 65, no. 7, pp. 769-781, 2018.

[126] U. Sen, T. P. Vacek, W. M. Hughes et al., "Cardioprotective role of sodium thiosulfate on chronic heart failure by modulating endogenous $\mathrm{H}_{2} \mathrm{~S}$ generation," Pharmacology, vol. 82, no. 3, pp. 201-213, 2008.

[127] J. Long, M. Liu, S. Liu et al., " $\mathrm{H}_{2} \mathrm{~S}$ attenuates the myocardial fibrosis in diabetic rats through modulating PKC-ERK1/2MAPK signaling pathway," Technology and Health Care, vol. 27, no. S1, pp. 307-316, 2019.

[128] X. Sun, D. Zhao, F. Lu et al., "Hydrogen sulfide regulates muscle RING finger-1 protein S-sulfhydration at $\mathrm{Cys}^{44}$ to prevent cardiac structural damage in diabetic cardiomyopathy," British Journal of Pharmacology, pp. 1-21, 2019.

[129] L. L. Pan, X. L. Wang, X. L. Wang, and Y. Z. Zhu, "Sodium hydrosulfide prevents myocardial dysfunction through modulation of extracellular matrix accumulation and vascular density," International Journal of Molecular Sciences, vol. 15, no. 12, pp. 23212-23226, 2014.

[130] L. L. Pan, X. H. Liu, Y. Q. Shen et al., "Inhibition of NADPH oxidase 4-related signaling by sodium hydrosulfide attenuates myocardial fibrotic response," International Journal of Cardiology, vol. 168, no. 4, pp. 3770-3778, 2013.

[131] P. K. Mishra, N. Tyagi, U. Sen, S. Givvimani, and S. C. Tyagi, "H2S ameliorates oxidative and proteolytic stresses and protects the heart against adverse remodeling in chronic heart failure," American journal of physiology- Heart and circulatory physiology, vol. 298, no. 2, pp. H451-H456, 2010.

[132] Y. X. Shi, Y. Chen, Y. Z. Zhu et al., "Chronic sodium hydrosulfide treatment decreases medial thickening of intramyo- cardial coronary arterioles, interstitial fibrosis, and ROS production in spontaneously hypertensive rats," American journal of physiology- Heart and circulatory physiology, vol. 293, no. 4, pp. H2093-H2100, 2007.

[133] B. Geng, L. Chang, C. Pan et al., "Endogenous hydrogen sulfide regulation of myocardial injury induced by isoproterenol," Biochemical and Biophysical Research Communications, vol. 318, no. 3, pp. 756-763, 2004.

[134] W. Hua, Q. Chen, F. Gong, C. Xie, S. Zhou, and L. Gao, "Cardioprotection of $\mathrm{H}_{2} \mathrm{~S}$ by downregulating iNOS and upregulating $\mathrm{HO}-1$ expression in mice with CVB3induced myocarditis," Life Sciences, vol. 93, no. 24, pp. 949-954, 2013.

[135] S. I. Bibli, I. Andreadou, A. Chatzianastasiou et al., "Cardioprotection by $\mathrm{H} 2 \mathrm{~S}$ engages a cGMP-dependent protein kinase G/phospholamban pathway," Cardiovascular Research, vol. 106, no. 3, pp. 432-442, 2015.

[136] N. Qipshidze, N. Metreveli, P. K. Mishra, D. Lominadze, and S. C. Tyagi, "Hydrogen sulfide mitigates cardiac remodeling during myocardial infarction via improvement of angiogenesis," International Journal of Biological Sciences, vol. 8, no. 4, pp. 430-441, 2012.

[137] C. K. Nicholson, J. P. Lambert, J. D. Molkentin, J. Sadoshima, and J. W. Calvert, "Thioredoxin 1 is essential for sodium sulfide-mediated cardioprotection in the setting of heart failure," Arteriosclerosis, Thrombosis, and Vascular Biology, vol. 33, no. 4, pp. 744-751, 2013.

[138] P. Ye, Y. Gu, Y. R. Zhu et al., "Exogenous hydrogen sulfide attenuates the development of diabetic cardiomyopathy via the FoxO1 pathway," Journal of Cellular Physiology, vol. 233, no. 12, pp. 9786-9798, 2018.

[139] S. Lilyanna, M. T. Peh, O. W. Liew et al., "GYY4137 attenuates remodeling, preserves cardiac function and modulates the natriuretic peptide response to ischemia," Journal of Molecular and Cellular Cardiology, vol. 87, pp. 27-37, 2015.

[140] G. Meng, J. Wang, Y. Xiao et al., "GYY4137 protects against myocardial ischemia and reperfusion injury by attenuating oxidative stress and apoptosis in rats," Journal of Biomedical Research, vol. 29, no. 3, pp. 203-213, 2015.

[141] G. Meng, J. Zhu, Y. Xiao et al., "Hydrogen sulfide donor GYY4137 protects against myocardial fibrosis," Oxidative Medicine and Cellular Longevity, vol. 2015, Article ID 691070, 14 pages, 2015.

[142] K. E. Sikura, L. Potor, T. Szerafin et al., "Hydrogen sulfide inhibits calcification of heart valves; implications for calcific aortic valve disease," British Journal of Pharmacology, pp. 1-17, 2019.

[143] C. Zhu, Y. Su, S. Juriasingani et al., "Supplementing preservation solution with mitochondria-targeted $\mathrm{H}_{2} \mathrm{~S}$ donorAP39 protects cardiac grafts from prolonged cold ischemia-reperfusion injury in heart transplantation," American Journal of Transplantation, vol. 19, no. 11, pp. 3139-3148, 2019.

[144] K. Kondo, S. Bhushan, A. L. King et al., " $\mathrm{H}_{2} \mathrm{~S}$ protects against pressure overload-induced heart failure via upregulation of endothelial nitric oxide synthase," Circulation, vol. 127, no. 10, pp. 1116-1127, 2013.

[145] D. J. Polhemus, Z. Li, C. B. Pattillo et al., "A novel hydrogen sulfide Prodrug, SG1002, promotes hydrogen sulfide and nitric oxide bioavailability in heart failure patients," Cardiovascular Therapeutics, vol. 33, no. 4, pp. 216-226, 2015. 
[146] D. Liang, H. Wu, M. W. Wong, and D. Huang, "Diallyl trisulfide is a fast $\mathrm{H} 2 \mathrm{~S}$ donor, but diallyl disulfide is a slow one: the reaction pathways and intermediates of glutathione with polysulfides," Organic Letters, vol. 17, no. 17, pp. 41964199, 2015.

[147] L. Yu, S. Li, X. Tang et al., "Diallyl trisulfide ameliorates myocardial ischemia-reperfusion injury by reducing oxidative stress and endoplasmic reticulum stress-mediated apoptosis in type 1 diabetic rats: role of SIRT1 activation," Apoptosis, vol. 22, no. 7, pp. 942-954, 2017.

[148] L. Yu, W. Di, X. Dong et al., "Diallyl trisulfide exerts cardioprotection against myocardial ischemia-reperfusion injury in diabetic state, role of AMPK-mediated AKT/GSK$3 \beta /$ HIF- $1 \alpha$ activation," Oncotarget, vol. 8 , no. 43, pp. 74791-74805, 2017.

[149] W. W. Kuo, W. J. Wang, C. Y. Tsai, C. L. Way, H. H. Hsu, and L. M. Chen, "Diallyl trisufide (DATS) suppresses high glucoseinduced cardiomyocyte apoptosis by inhibiting JNK/NF $\kappa B$ signaling via attenuating ROS generation," International Journal of Cardiology, vol. 168, no. 1, pp. 270-280, 2013.

[150] R. A. Frieler and R. M. Mortensen, "Immune cell and other noncardiomyocyte regulation of cardiac hypertrophy and remodeling," Circulation, vol. 131, no. 11, pp. 1019-1030, 2015.

[151] S. Frantz, K. Hu, A. Adamek et al., "Transforming growth factor beta inhibition increases mortality and left ventricular dilatation after myocardial infarction," Basic Research in Cardiology, vol. 103, no. 5, pp. 485-492, 2008.

[152] X. Zhang, Z.-G. Ma, Y.-P. Yuan et al., "Rosmarinic acid attenuates cardiac fibrosis following long-term pressure overload via AMPK $\alpha /$ Smad3 signaling," Cell Death \& Disease, vol. 9, no. 2, pp. 102-102, 2018.

[153] Q. Y. Zhang, H. F. Jin, S. Chen et al., "Hydrogen sulfide regulating myocardial structure and function by targeting cardiomyocyte autophagy," Chinese Medical Journal, vol. 131, no. 7, pp. 839-844, 2018.

[154] K. Kashfi and K. R. Olson, "Biology and therapeutic potential of hydrogen sulfide and hydrogen sulfide- releasing chimeras," Biochemical Pharmacology, vol. 85, no. 5, pp. 689703, 2013.

[155] M. Bilban, A. Haschemi, B. Wegiel, B. Y. Chin, O. Wagner, and L. E. Otterbein, "Heme oxygenase and carbon monoxide initiate homeostatic signaling," Journal of Molecular Medicine, vol. 86, no. 3, pp. 267-279, 2008.

[156] L. M. D. Delbridge, K. M. Mellor, D. J. Taylor, and R. A. Gottlieb, "Myocardial stress and autophagy: mechanisms and potential therapies," Nature Reviews Cardiology, vol. 14, no. 7, pp. 412-425, 2017.

[157] D. Wu, H. Wang, T. Teng, S. Duan, A. Ji, and Y. Li, "Hydrogen sulfide and autophagy: a double edged sword," Pharmacological Research, vol. 131, pp. 120-127, 2018.

[158] S. Sestito, G. Nesi, R. Pi, M. Macchia, and S. Rapposelli, "Hydrogen sulfide: a worthwhile tool in the design of new multitarget drugs," Frontiers in Chemistry, vol. 5, p. 72, 2017.

[159] S. B. Montesi, P. Désogère, B. C. Fuchs, and P. Caravan, "Molecular imaging of fibrosis: recent advances and future directions," The Journal of Clinical Investigation, vol. 129, no. 1, pp. 24-33, 2019.
[160] M. Abdelmonem, N. N. Shahin, L. A. Rashed, H. A. A. Amin, A. A. Shamaa, and A. A. Shaheen, "Hydrogen sulfide enhances the effectiveness of mesenchymal stem cell therapy in rats with heart failure: In vitro preconditioning versus in vivo co-delivery," Biomedicine \& pharmacotherapy, vol. 112, article 108584, 2019.

[161] T. L. Guidotti, "Chapter 8- Hydrogen Sulfide Intoxication," in Handbook of Clinical Neurology, M. Lotti and M. L. Bleecker, Eds., pp. 111-133, Elsevier, 2015. 